\title{
Teachers as Managers of the Modelling Process
}

\author{
Thomas Lingefjärd \\ University of Gothenburg
}

\author{
Stephanie Meier \\ Technische Universität, Dortmund
}

\begin{abstract}
The work in the Comenius Network project Developing Quality in Mathematics Education II (DQME II) has a main focus on development and evaluation of modelling tasks. One reason is the gap between what mathematical modelling is and what is taught in mathematical classrooms. This article deals with one modelling task and focuses on how two teachers handle this task in their classrooms. Initially, the notion of a teacher being the manager of the learning process is elaborated. Using criteria developed from taking this perspective, we analyse classroom sequences to determine the nature of "teaching like a manager" and the actions that are classroom evidence for working in this way. Conclusions include recommendations for how to realise "acting like a manager" in mathematics classrooms.
\end{abstract}

While mathematical modelling is part of the school curricula in most of the partner countries of the Comenius Network project Developing Quality in Mathematics Education II (DQME II), the gap between the ideal of how to teach mathematical modelling and what is happening in the classrooms is huge. This has been underlined by the results of international studies like PISA and TIMMS. The aim of our Comenius Network, to develop modelling tasks and test those in classrooms in different European countries with different teaching methods, resulted from the construct "mathematical literacy" defined in the PISA framework (Organisation for Economic Cooperation and Development [OECD], 2003) as:

an individual's capacity to identify and understand the role that mathematics plays in the world, to make well-founded judgements and to use and engage in mathematics, in ways that meet the needs of that individual's life as a constructive, concerned, and reflective citizen. (p. 24)

The objective of allowing students to learn "the role mathematics plays in the world" is widely represented by the goals of using modelling tasks in school mathematics classrooms. The modelling cycle of Blømhoj and Jensen (2007), for example, indicates that modelling tasks should have a close connection to reality, and that the step from the perceived reality to a mathematical domain of inquiry is an important part of the modelling circle. This step is something students should learn, since it also underlies the OECD definition of mathematical literacy. To support students in learning this step, modelling tasks representing an area of real life in which professionals deal with mathematics are, of course, very helpful.

\section{The Study Design}

The Sun Hour Problem (see Figure 1) is one example from the DQME II project being used in countries in the Comenius Network. It was developed through mutual exchange between a teacher from Sweden and a teacher from Germany. More details can be found in Andersson, Lingefjärd, Meier, and Müller (2009). 
Sunrise is the instant at which the upper edge of the Sun appears above the horizon in the east. Because atmospheric refraction causes the sun to be seen while it is still below the horizon sunrise is seemingly an optical illusion. The sun also appears larger on the horizon, but this is another optical illusion, similar to the moon illusion. The apparent westward revolution of the Sun around the Earth after rising out of the horizon is due to the Earth's eastward rotation, a counter-clockwise revolution when viewed from above the North Pole. This illusion is so convincing that most cultures had mythologies and religions built around the geocentric model. As sunrise and sunset are calculated from the leading and trailing edges of the Sun, and not the centre, this slightly increases the duration of "day" relative to "night". Compare: http: / / en.wikipedia.org/wiki/Sunrise

Tasks: Form a group of 4 and work on a suitable mathematical model to describe the phenomenon of sunrise/sunset and the change of the daylight time for your town and others. The model should be able to account for differences in location. Describe situations in which this model could be useful and how it could be used.

A possible work outline: Find a table with times for sunrise and sunset for your towns. Use some kind of tool for displaying your data. Try to find a model that is applicable for determining the number of daylight hours at your location. How would your model change if you went to cities with different longitude and/or latitude?

Time frame: Maths classes during week 50-51 will be devoted to this task. On the 8th of January a full day will be set aside for your work. During this day you are also required to present your work to the rest of the class.

Figure 1. The Sun Hour Problem.

The student task was to form groups and work on a suitable mathematical model to describe the phenomenon sunrise/sunset and the change of the daylight time for their hometown as well as for some other locations. The model should be able to account for differences in location. We argue that this task fulfils the criteria for a modelling task as it is described above, mainly because mathematical models describing that phenomenon exist, and astronomers have to deal with and develop such models.

The teachers not only agreed on the task to be given to the students, but also on the teaching method. The task was very open and the teachers decided to support the students during their modelling process without pushing them in a specific direction; that is, they wanted to support the students in finding their own mathematical model without telling them which one they would prefer. This was the starting point for our research about teachers acting like managers of the learning process, in which we observed two teachers who voluntarily agreed on using the open modelling task, and a student-centred teaching method.

Our research involved addressing the questions:

1. How is "teaching like a manager" defined?

2. Did the two teachers act like managers? 
In order to create a theory about what teaching like a manager means, we consulted different literature sources dealing with teacher and student interaction in mathematics classrooms, as well as sources explaining the role of managers. With the aim of analysing the complex interaction between teachers and students in a classroom, we examined videos and transcripts from classrooms where modelling tasks were being undertaken using Goffman's frame analysis of communication (Goffman, 1974/1986) as well as the theory we had developed about teaching like a manager.

In this article, the theoretical background will be detailed first. The second part describes the analysis of teachers' actions during modelling lessons in target classrooms in Sweden and Germany, which follows a short discussion of the classroom circumstances with which the teachers had to deal. Finally, a discussion of the analysis of the teachers' actions during the lessons in Sweden and Germany will be presented.

\title{
Theoretical Background
}

\section{Notion of a "Teacher as a Manager" of the Modelling Process}

Many different theoretical frameworks can be applied to classroom situations like the ones in this study, in which we focused on the teachers' actions while their students were dealing with a very open modelling assignment. The teachers decided not to instruct their students directly, but to support them in trying to find data, in devising their own questions, implementing their existing knowledge, and developing a model concerning the real world problem. The following description from Barnes (2000, p. 40) of a teacher in an Australian study parallels how teachers in our study acted:

\begin{abstract}
As groups brainstormed and developed their ideas, the teacher moved around, listening to and sometimes joining in group discussion. She asked questions to elicit progress, to help students clarify their understanding, to prompt them to elaborate their explanations, to help groups refocus and so facilitate a breakthrough, to encourage generalisation or extension of the original problem, or to elicit evaluation; but avoided answering questions, giving hints or indicating whether an explanation or an approach to a problem was correct. She made a habit of asking a question and then walking away, leaving the group to think about it for themselves.
\end{abstract}

Ball and Bass (2000) describe a teacher's background and teaching very well for our purposes, using three commitments about the nature of mathematics teaching and learning:

First is the commitment to treat the discipline of mathematics with integrity; a second is to give serious respect to children's mathematical ideas, and a third commitment is to see mathematics as a collective intellectual endeavour situated within a community. (p. 197)

These three commitments define a position within which teachers need to talk less and tell students less, and create situations in which students can construct relevant mathematics themselves. We, as the researchers, wanted to observe how the two teachers realised this, and in doing so we developed the idea of a teacher acting like a manager of the modelling process. 


\section{Theory of a "Teacher as a Manager" of the Modelling Process}

To find criteria for our theory of a teacher as a manager of the modelling process we decided to look first at the work of Leiß. The starting point for his work was a quote attributed to Maria Montessori, and referred to by (Leiß, 2005, p. 240) as "one of the best-known quotes in pedagogical literature: 'Help me to do it myself.'" This was the main focus used by Leiß when analysing teacher intervention in mathematics classrooms, and is, in our opinion, the main purpose when a teacher acts as a manager of the learning process. To structure the analysis Leiß created a diagram (Figure 2, translated by Meier) illustrating the process of teacher intervention (reading from right to left). In this diagram Leiß identifies the following four categories of teacher intervention: affective, metacognitive, related to content, and related to organisation.

\begin{tabular}{|l|l|l|l|}
\hline $\begin{array}{l}\text { Problem } \\
\text { in the } \\
\text { process of } \\
\text { learning }\end{array}$ & $\begin{array}{l}\text { Knowledge about } \\
\text { the problem } \\
\text { situation } \\
\text { or }\end{array}$ & $\begin{array}{l}\text { Teacher intervention: } \\
\text { affective } \\
\text { organisational } \\
\text { metacognitive } \\
\text { content-related } \\
\text { diagnosis of the } \\
\text { problem situation } \\
\text { (intention, time, addressed to...) }\end{array}$ & $\begin{array}{l}\text { Further self- } \\
\text { dependent work } \\
\text { on the solution }\end{array}$ \\
\hline
\end{tabular}

Figure 2. The ideal process of teacher intervention (from Leiß, 2007, p. 82).

Before intervening the teacher has to make a diagnosis, so Leiß added a fifth category, which is called "diagnosis", and later gave a definition of what he calls "adaptive" teacher intervention:

An adaptive teacher intervention means the introduction of (on the basis of knowledge and/or diagnosis of the teacher) a content related and methodologically minimal intervention into the individual solving process of the student, whereby the student is enabled to overcome a (potential) barrier in his or her learning process and to go on working independently.

(Leiß, 2007, p. 82, translated by Meier)

This adaptive teacher intervention can have the intention of affective, organisational, metacognitive or content related support.

In our opinion the definition of adaptive teacher intervention including the last three categories (organisational, metacognitive and content-related support) belong to what we would call a "teacher as a manager" of the modelling process. This occurs when the teacher tries to understand what the students are working on (metacognitive intervention) and discusses the problems the students have with the task without telling them how to solve the problem. The teacher gives, in Leiß's words, a "methodological minimal intervention into the individual solving process of the student, whereby the student will be made able to overcome a (potential) barrier" (2007, p. 82, translated by Meier).

In studying the interaction between teachers and students, Doerr (2006, p. 257) analysed mathematics classrooms via video recording and described how teachers see and interpret students' ways of thinking as well as how 
teachers' interpretations of students' thinking influence their actions in the classroom. One of the main tasks to understand in handling students' solutions to mathematical modelling tasks is not only to grasp the mathematics in the students' presentations, but also to simultaneously devise an appropriate response. For this, "the teacher needs to have a broad and deep understanding of the diversity of approaches that students might take" (Doerr, 2007, p. 76). This skill is necessary for a teacher so that he or she can put the students in situations where they can interpret, explain, justify and evaluate, and refine and revise their different models. In Doerr's view this change in pedagogical strategy is a major shift from more traditional instruction in mathematics. However, she leaves open where this shift may lead to by suggesting that teacher education programs need to address both the subject matter knowledge of teachers, and the development of new kinds of pedagogical knowledge (p. 77). These new kinds of pedagogical knowledge address the following four characteristics of teachers' knowledge, relevant to the teaching of mathematical modelling: to be able to listen for anticipated ambiguities; to offer useful representations of student ideas; to hear unexpected approaches; and to support students in making connections to other representations (Doerr, 2007, p. 77).

The third focus of our theory is the definition of "manager", for example, as described in various industrial sources. According to the Business dictionary, a manager is:

An individual who is in charge of a certain group of tasks, or a certain subset of a company. A manager often has a staff of people who report to him or her. As an example, a restaurant will often have a front-of-house manager who helps the patrons, and supervises the hosts. In addition, a specific office project can have a manager, known simply as the project manager. Certain departments within a company designate their managers to be line managers, while others are known as staff managers, depending upon the functionality of the department. (Business dictionary, 2010)

Another more succinct definition is the following: "A manager is a person who performs management tasks in an organization. The main tasks of management are planning, organization, management and control" (Wikipedia, 2010). Based on these descriptions, as the first step a teacher as a manager of the modelling process has to plan, organise and manage the learning process. What she or he should not do is, to instruct the students and tell them how the problem can be solved.

Teaching as a manager should, in our opinion, include the following: The teacher should be able to support the students in an adaptive way; give organisational, metacognitive and content-related support according to Leiß's theory (2007); use Doerr's (2007) four characteristics of pedagogical knowledge to provide content-related support; offer useful representations of student ideas; and support students in making connections to other representations. If teachers do this they are able to give not only contentrelated support, but also organisational and metacognitive support.

Obviously there are both similarities and deep differences between being a manager in a business company and being a manager for the learning process in a school. The main difference is that a business manager normally gives advice and does not discuss approaches with his or her 
employees. We postulate that a teacher as a manager of the modelling process has to do the latter.

\section{Analysing Classroom Communication}

In order to understand how the management influenced the students' work, we also analysed the communication which took part in the working groups. One way to try to understand what is going on in the communication and interaction between a teacher and students or between students is to view the situation as a part of what Goffman (1974/1986) calls the framing of a social situation.

I assume that definitions of a situation are built up in accordance with
principles of organization which govern events - at least social ones - and
our subjective involvement in them; frame is the word I use to refer to such
of these basic elements as I am able to identify. That is my definition of
frame. My phrase "frame analysis" is a slogan to refer to the examination in
these terms of the organization of experience. (Goffman, 1974, pp. 10-11)

According to Goffman, every situation is defined in a way that participants share and often take for granted. This is called a frame and can, in general, be seen as the participants' mutual response to the question: "What is going on here" (Goffman, 1974/1986, p. 8)?

Given their understanding of what it is that is going on, individuals fit their action to the understanding and ordinarily find that the ongoing world supports this fitting. These organizational premises - sustained both in the mind and in activity - I call the frame of the activity. (Goffman, 1986, p. 247)

Framing also includes the students' perspective on the situation they are a part of. The situation when students are engaged in a mathematical modelling project in a classroom is by no way extraneous to their activity, indeed this is what structures what the students are trying to accomplish. The frame of the situation includes how students read instructions, their attention, their outcome, and their involvement in the situation.

To analyse a situation with the concept of framing means looking at an activity and searching for an indication of what this activity means to the participants. Shifts of framing, frame conflicts and frame clearing are activities that can be identified by studying the responses, including which questions elicited those responses. A shift of framing occurs when a dialogue goes from one point of view to another, for example, from a mathematical point of view to a social point of view. Frame conflicts arise from this and become obvious when two persons interacting do not understand each other. If that happens the frame has to be cleared by one of those who are interacting. This then makes it possible to discern what was relevant for the speaker and thus analyse how the participants framed the utterances in the activities (cf. Lantz-Andersson, 2009).

In our opinion, the ability to frame a situation and to identify shifts of framing, frame conflicts and especially frame clearing, are all competences that a "teacher as a manager" of the modelling process should have. These competences have to be added to those mentioned above. The teacher has to keep the students in the current mathematical frame and decide when it is acceptable or perhaps necessary to shift the frame. He or she has to 
coordinate the work of the students and if a conflict arises, to understand the conflict and clear the frame.

To connect this with Doerr's (2007) words: If the teacher listens to the students and hears unexpected approaches he can frame the situation or clear frames or even frame the problems of the students to help them understand their "potential barrier". So the teacher can only give organisational, metacognitive or content-related support, if he or she recognises the students' discussion and is able to frame situations and decide if framing a problem, clearing the frame or maybe a shift of the frame is necessary to help the students find their way. This can result in offering new representations or helping to connect to other representations.

\section{Classroom Circumstances}

A teacher from Sweden and a teacher from Germany taking part in the DQME II project will be the focus of our analysis. Both teachers gave their students (aged 17-18 years old) the Sun Hour task before the Christmas break so that they had two sessions to prepare the group work for the project day in January. The groups decided on which element they wanted to focus. During the first day they had four lessons to search for and collect information on the internet, and another two to present their mathematical models.

The students had a basic knowledge of calculus, including trigonometry, which was needed for this modelling project. Both the classroom in Germany and in Sweden had computers and wireless internet connections. Furthermore, the students had previous experience working with the mathematical computer software Graphmatica and Excel. Graphmatica has an inbuilt curve-fitting tool that makes it possible to fit a polynomial, an exponential, and trigonometric or power functions to experimental data. (See www.graphmatica.com). The instructions were handed out together with a short introduction of the project. Most groups managed to find appropriate data for the times of the sunrise and sunset for their own location. During the full-day session a few different approaches to the problem were represented in the Swedish classroom. Most groups had focused on trying to model the variation of the daylight hours through a trigonometric model. This is done quite easily once all of the data have been entered into Graphmatica. The challenge, however, lies more in adapting the model to different latitudes. In the German classroom the students focused on very different aspects of the problem. The presentation gave them a good overview about the problem of modelling the variation of the daylight hours.

Both teachers were experienced in using modelling tasks in their classes. Moreover, both regularly used teaching methods where students worked on their own. This time the only difference was that they wanted to focus on supporting the students in their problem solving process, without telling or pushing them towards one specific solution. 


\section{Classroom Analysis in Germany and Sweden}

The following analysis of exemplary scenes from a German and a Swedish classroom will be conducted using the frame analysis of Goffmann $(1974 / 1986)$ and the concept of adaptive teacher intervention according to Leiß (2007). During the observed classroom sessions in both countries, the students had about 90 minutes to finish the projects and to prepare their presentations. All students were fluent in German or Swedish. The group members are labelled Student 1, Student 2, Student 3, Student 4, and Student 5. In translating what the students said from German or Swedish into English, the essence of what the students meant was considered. In many cases, the translation is verbatim, but an effort has been made to use translated words that seem suitable for the context at hand. Figures in brackets are numbered items from the transcript, illustrating that this article draws on only some of the discussion that took place. Obviously it is a major challenge to avoid using one's a priori assumptions to select and analyse some parts of the transcripts, thereby also neglecting other parts. It is also important to realise that the observer's presence most likely affects the framing or social structure of the situation.

Both teachers decided not to instruct the students, but to support them to find a solution. We will not distinguish between the countries in our analysis, but rather between the teachers.

\section{Interventions by Teacher 1}

Teacher 1: So that is what you wrote down according to some data? [1]

Student 5: Yes. [2]

Teacher 1: Great. So you are proceeding forward? [3]

Student 6: So far. [4]

Teacher 1: Any questions? Something not clear? [5]

Student 6: So far everything is fine. [6]

Student 5: We do not know what is coming afterwards. [7]

Teacher 1: So you call me then? [8]

Student 5: Yes. [9]

This is an example of a diagnostic question from the teacher. He wants to find out if there is a problem that needs to be clarified, before the students can go on working. He made sure that if there are any questions occurring they can ask him. Nevertheless, what he is not doing is telling the students how they can continue working. They have a result and are still adjusting this result, but they had not yet thought about how to proceed next. So the teacher's intervention can be identified as an affective intervention: He made sure that there were no questions at that time, that the students had a good result and that he thought they could continue on their own without his help for the first step. There was no frame to clear or any unexpected 
approach to talk about. The students now have to develop another idea on their own, before the teacher can react to that.

In a second situation some other students asked the teacher to come and to have a look at their results.

Teacher 1: What are you doing? What is that? (On the screen) [10]

Student 3: That is our diagram. Sunrise, sunset and sun hours per day. [11]

Teacher 1: And you have the data from some tables? Did you simplify the data? (...) [12]

The teacher asked what they had done and what the diagram represented. Furthermore, he asked what kind of data they had used. With this question he started a content related frame conflict, after which one of the students realized that there was a crazy number in their diagram.

Student 3: Look here is written 23.78, that cannot be ... [13]

Student 4: It was not possible to type in the time, because ... [14]

Student 3: that leads to 100 and not to 60. [15]

Student 4: Right. There are only 60 minutes, not 100. [16]

The teacher tried to clear that frame; but what happened was that the students cleared the frame instead.

Teacher 1: Then recalculate that. [17]

Student 4: That is what we did and why we have now data with .78. [18]

Teacher 1: So 0.78 is the part of an hour? [19]

Student 3: Yes. [20]

Teacher 1: Then calculate into parts of a minute. [21]

Student 4: But then we cannot display that in a diagram, because then it is not hundredth but parts of sixty, which is written after the comma (equivalent of decimal point). [22]

Student 3: And that does not fit. [23]

Teacher 1: I see. So that is what you have to think about. I see the problem and I understand it. Try to find a solution. [24]

Once again the teacher told his students that he understood their work, and that he thought that they had found a good problem and framed a good problem and that he thought that they were able to deal with it on their own. In this sense, the teacher helped the students to do it themselves. However, during the presentation it was not obvious if those students actually found a solution for that problem.

In a third intervention the teacher gave much more content-related help to the student.

Student 1: Now I am missing the $H$, which is the height above the horizon. Below in this example (...) $\mathrm{H}$ equals minus 50 arc minutes. But where do these arc minutes come from? (He is working with an Internet Website.) [25] 
Teacher 1: Yes, but think about that, 50 arc minutes [26]

Student 1: minus 50. [27]

Teacher 1: That does not matter. You should figure that out. You know what an arc is, don't you? [28]

So the teacher not only gave content-related help, but also tried to help the student to frame the problem. This did not work so the teacher stayed with them giving content-related help in the following part of their discussion.

Student 1: Yes. [29]

Teacher 1: And this arc is divided into degrees. [30]

Student 1: Yes. [31]

Teacher 1: And an hour has 60 minutes. [32]

Student 1: $\quad$ So it is just degree? [33]

Teacher 1: Sure. You now have to find the link between... Remember that hours and minutes do not have a special subdivision without good reasons. Time is subdivided in parts of 60. [34]

Student 1: Yes. [35]

Teacher 1: And there is a good way to connect arc minutes with degrees. And if you now google how to calculate arc minutes, you will see what arc minutes have to do with the circumference of the circle. [36]

(Some searching with Google followed.)

After they found a good result indicating how to calculate arc minutes, the teacher again tried to frame the problem and to let the student find the answer.

Teacher 1: Is that helpful? You now should be able to calculate that. (...) The 60th part of one degree is named an arc minute. And you can calculate the arc. [37]

Student 1: But the arc of what? [38]

Teacher 1: Of the circle. [39]

Now the student was able to ask a question to show the teacher what his problem was and he tried to make his problem more concrete.

Student 1: But I have now only the degree of those. And I have to find a starting point. Some kind of numbers, which I can use as a ground basis. [40]

Teacher 1: Yes, what you need is a unit circle, a circle with the radius 1, that has the circumference of 2 pi. [41]

Student 1: Yes. [42]

Teacher 1: And now you subdivide it into 360 degrees. [43]

Student 1: Yes. [44]

Teacher 1: And now you can calculate the arc for one degree. For that you have to divide 2 pi by 360 . What is the result? [45] 
Student 1: Too little. [46]

Teacher 1: Calculate. [47]

Teacher 1: What is the result? [48]

Student 1: $\quad 0.1375 \ldots[49]$

Teacher 1: And do you know now how to go on? [50]

What is obvious in the last part of this interaction is that the teacher now tried to give content-related hints to make the student understand the problem. So he tried to clear the frame with direct content-related help.

Student 1: No. [51]

Teacher 1: Why not? [52]

Student 1: I do not know how to use that result. [53]

Teacher 1: Then let us have a look at that little window again. (On the screen) [54]

(...)

Teacher 1: You have to divide the last result by 60. (...) How many arc minutes are there? [55]

Student 1: Minus 50. [56]

Teacher 1: Then multiply this result with minus 50. You are a really smart guy. [57]

According to the teacher's opinion the frame is now cleared by having a result that is also displayed at the Internet page; but the student was not happy with that and framed another problem.

Student 1: But where do these minus 50 arc minutes come from? [58]

Teacher 1: That is the next question. [59]

So the teacher motivated the student to work on his own on the next problem. The teacher wanted the student to work on that problem including all the content-related information he received during their discussion. During this intervention the teacher gave much content-related help. However, in between he also tried to frame a problem for the student so that the student could find a way to solve the problem on his own. The student was able to explain to the whole class the concept of arc minutes during his presentation.

\section{Interventions by Teacher 2}

The presentation session started with the students gathered around computers at small tables, where they sat and discussed their solutions and how they wanted to present them to the whole class. The teacher stood at the back of the classroom, observing the students working. One of the groups called for him and the following conversation took place:

Student 1: We have a rather weird formula here, should we really present it? [3] 
Teacher: What do you mean? [4]

Student 2: Well, we are unsure about if we really understand it ourselves. It is a little bit difficult to follow. [5]

Teacher: Well, if it is your formula, then go ahead and explain it! [7]

(The three students look around at each other and it is obvious that they are in a bad mood; but the teacher walks away to another group.)

Student3: I guess if we do it quickly enough, no one will be fast and smart enough to ask a critical question. [9]

(Student 1 picks up a paper and pencil and draws some signs on it and says:) Yes, you can just write $\mathrm{A} \propto \mathrm{TP} / \mathrm{h}$ or $\mathrm{A}=\mathrm{TP} / \mathrm{h}$. [10]

This intervention by the teacher we identify as an affective intervention. The teacher made sure that there were no more immediate questions and left it to the students to decide what to do without his help. The students handle the situation by clearing the mathematical frame and moving into a social frame. However, when presenting, it was obvious to the whole class that this group never found a useful model. When the teacher was aksed about this by the researchers, he responded by quoting the curriculum (as already mentioned): The students should learn to "work on their own and analyse, perform and present orally and in written form, a more comprehensive assignment where knowledge from different mathematical areas are involved" (Skolverket, 2009, p. 1).

Another group stumbled with the quality of their model. They asked the teacher to come over and one of the students told him:

Student 5: You said something about curve fitting last time. How do we know that our model is good? [13]

Teacher: Well, you can always have a look at the $\chi^{2}$ value: [14]

The teacher is trying to avoid the question by making a rather vague suggestion and he tries to leave but is stopped by Student 5, who has more questions.

Student 6: (picks up a calculator and asks) I have another number, called $r$, here in the calculator. Is that the same? [15]

Student 5: I am not sure that I understand what this $\chi^{2}$ means. We have a value of $\chi^{2}$ which is over 1200 . Is that good? [17]

We interpret this dialogue as an example of how the teacher is trying to clear the mathematical frame, while Student 5 and Student 6 are objecting and fighting to keep the mathematical frame open.

The students had worked with Graphmatica, carried out a "curve fitting procedure" and now the computer is telling them something about $\chi^{2}$ which is something the students do not understand and cannot interpret for their task. This means that the tool shapes the thinking of its users; in the words of Goffman(1974/1986) the computer is framing a problem.

Student 7: Can someone explain what we are talking about here? [17] 
Student 5: Well, I think that you (the teacher) told us last week that any mathematical model can fit better or worse and therefore you need to have a quality control and that is what we have in this $\chi^{2}$. But what is $r$ ? Is it the same? [19]

(Student 5 looks at the teacher who looks away, obviously rather disconcerted by the question.)

Student 7 and Student 8 are stumbling between frames in utterances [14] to [19].

Student 6: Right. So we have a quality of 1200, is that what you are a saying? [21]

Teacher 2: Yes, that is correct. Now, please excuse me. [22]

The teacher obviously tried to avoid questions about $\chi^{2}$ values and the regression coefficient and the teacher's intervention serves therefore to "throw the ball back" to the students in Leiß's words (2007, p. 242). Therefore the students are forced to operate in the mathematical framing all by themselves. The teacher did not clear the frame.

Student 5: Well, maybe we need to check that number somehow. Wasn't there a table or something? [24]

Student 6: Here, check my calculator. This $r$ value is pretty low? See here. [25]

The students were stumbling within the mathematical framing, more or less lost when trying to figure out the connection between $\chi^{2}$ and $r$. That was probably an unexpected situation for both the teacher and the students, and it took a while before the students started to act.

Student 5: I read here at Google that the value of $\chi 2$ should be low and the value of $r$ should be close to 1 . We are in trouble here. It is like we have 1200 and should have 12 ! We need to do something! [28]

This throwing the ball back by the teacher did not work well and it was as if all the students suddenly lost their spirit and all members of the group looked rather unmotivated - what Leiß calls stimulated recall (2007, p. 242). The silent group member, the "computer", told the students that they did something wrong in their work.

Goffman (1974/1986) suggests that when we face situations where the framing is problematic, we end up in uncertainty about how to act in that situation; we do not understand the situation. As a result, the group became silent and especially Student 7 and Student 8 seemed rather lost and quite uncertain about how to frame this situation. Suddenly Student 5 took command.

Student 5: This is what we must do. There is no way that we can redo all the work we have done and try to find where our error is. Maybe there is more than one error. It is also unfair that we did not get this information earlier. We have to present our model but we do it in a way that doesn't bring any attention to the $\chi^{2}$ value whatsoever. All right? [30] 
The students reacted to the teacher's intervention by making the silent group member much more silent by hiding the problematic value in their calculation. On the other hand, the students did manage to handle the teacher's intervention by shifting from an uncertain mathematical framing into a more secure social framing, Student 5 brought the group back into the play and they actually delivered a good presentation in which they succeeded to say nothing about the mathematical modelling experience but a lot about the number of sun hours in Addis Abbaba. The teacher, also quite uncertain about the sun movement in the sky, about $\chi^{2}$ values and about regression coefficients, evaluated their presentation with a good mark.

\section{Discussion}

What we found during the analysis of the two classrooms were diagnostic questions by the teachers, content-related help to frame a problem or to clear a frame, framing problems to support the students and affective intervention by assuring the students that they can solve the problem on their own. Comparing this with Doerr's (2007) four characteristics of teacher's knowledge we can say that the teachers listened to the students' ideas, tried to discover anticipated ambiguities and to hear unexpected approaches. We also see the framing of problems and the clearing of frames in the teachers' diagnostic questions. Furthermore, we discovered situations in which the teacher offered useful representations or made connections to other representations.

Another competence a teacher should have, according to Doerr (2007), is to grasp the mathematics in the students' presentations and devise an appropriate response. We think that this is a really hard requirement, which also becomes obvious in our analysis. There are different factors that affect this: on the one hand it could happen that the teacher did not grasp the mathematics in the students' presentations or maybe misunderstood it, or he or she thinks that the mathematics is too difficult for the students to understand. The first factor can be seen when the students clear frames in the dialogue with the teacher. So the teachers' task is also to take time to listen to the students' solutions. The second factor can be seen when the teacher, for example, tells the students that the underlying mathematics is too difficult, or if the teacher avoids answering a question. This is a possible explanation for teacher 2 not answering the question about $\chi^{2}$.

Moreover the last sequence with teacher 1 shows that it is sometimes necessary to support students with content-related help and to not just assume that they are able to find a solution themselves. In this case, the student showed in his presentation that he understood the mathematical content he worked on.

\section{Conclusion}

When using a complicated mathematical modelling project for students in their teaching, the teachers in both Germany and Sweden adopted a more coaching-inspired teaching method and allowed the students to move in different ways. Our intentions with the study and the article were to answer the two questions: What does "teaching like a manager" look like? Did the 
two teachers act like managers? We intended to create a first idea about what a teacher as a manager of the modelling process looks like. We did this by connecting several existing theories (Doerr, 2006, 2007; Leiß, 2005, 2007) about teacher intervention during modelling processes. This theory was the basis for the analysis of both classrooms.

We are aware that the teachers in the two different classrooms did not act as managers during the whole lesson. Perhaps this is impossible without external supervision. We can look, for instance, at the situation where teacher 2 told the students to explain their formula, if that is even their formula, without giving more support. He acted just as the curriculum asks for and as both teachers had agreed to act; but the students were lost without more support. He might have asked the students to explain the formula to him and then to try to clear the frame.

Furthermore, when trying to detect if the students in any of the classrooms really overcame a barrier in their minds, referring to Leiß's (2007) theory, we are unsure if this really happened. It probably needs a directed approach from the teachers to address a specific barrier he or she wants the students to break through.

By analysing such encounters, we hope we can help teachers to develop ideas about how to support their students, without telling them how to solve the problem at hand and also without leaving their students alone. In other words: helping the students know how to do it themselves and how to become good problem solvers.

On one hand, we found examples of teacher and student interactions in which the teacher did not tell the students how to do it, but tried to frame the problem, to make the problem easier to handle for the students. On the other hand, it also became obvious that acting as a manager is not as easy as it sounds. By examining the students' actions after the teacher did not give the consequent content-related help or a good hint at how to solve the problem, it is apparent that the students stopped trying to solve the mathematical problem mathematically. Instead, they started to solve it in a social frame or by just ignoring it. So only telling the students "I believe that you will find a solution" is not necessarily a successful move for a teacher acting as a manager.

One important conclusion for us is that it is obviously not enough to ask the teacher to avoid giving a solution to their problem. The teacher needs more information, training and supervision about how to act in specific situations. He or she needs a bundle of possibilities from which he/she can choose, and he/she also needs to be both well educated in mathematics and in teaching methods. One way to achieve this would be for teachers in mathematics and researchers in mathematics education to work closely together. Another possibility would be to ask a colleague to visit one's classroom and ask for feedback. These suggestions for closer cooperation are consistent with similar recommendations that have arisen in a variety of other studies. Nevertheless, our findings support the view that working with mathematical modelling tasks gives rich opportunities to try another teaching role, and it gave us hope to observe that the teachers in our study tried hard to act as managers, for purposes of seeking new ways to enhance the modelling process. 


\section{References}

Andersson, M., Lingefjärd, T., Meier, S., \& Müller, J. H. (2009). The sun hour project. In W. Henn, \& S. Meier (Eds.), Growing mathematics. Dortmund, Print on demand.

Ball, D., L., \& Bass, H. (2000). Making believe: The collective construction of public mathematical knowledge in the elementary classroom. In D. Phillips (Ed.), Yearbook of National Society for the Study of Education, Constructivism in Education (pp. 193-224). Chicago, IL: University of Chicago Press.

Barnes, M. (2000). 'Magical' moments in Mathematics: Insights into the process of coming to know. For the Learning of Mathematics, 20(1), 33-43.

Blømhoj, M., \& Jensen, T. H. (2007): What's all the fuss about competencies? In W. Blum, P. Galbraith, H.-W. Henn, \& M. Niss (Eds.), Modelling and Applications in Mathematics Education. The 14th ICMI Study (pp. 45-56). New York: Springer.

Doerr, H. M. (2006). Teachers' ways of listening and responding to students' emerging mathematical models. ZDM, 38(3), 255-267.

Doerr, H. (2007). What knowledge do teachers need for teaching mathematics through applications and modeling? In W. Blum, P. Galbraith, H.-W. Henn, \& M. Niss (Eds.), Modelling and applications in mathematics education: The 14th ICMI Study(pp. 69-78). New York: Springer.

Goffman, E. (1974/1986). Frame analysis: An essay on the organization of experience. Boston, MA: Northeastern University Press.

Lantz-Andersson, A. (2009). Framing in educational practices: Learning activity, digital technology and the logic of situated action (Gothenburg Studies in Educational Sciences, No. 278). Göteborg, Sweden: Acta Universitatis Gothoburgensis.

Leiß, D. (2005). A classification of teacher interventions in mathematics teaching. ZDM, 37(3), 240-245

Leiß, D. (2007). "Hilf mir es selbst zu tun" - Lehrerinterventionen beim mathematischen Modellieren [Help me to do it myself - Teacher interventions in mathematical modeling]. Hildesheim, Germany: Verlag Franzbecker

Manager (n.d.). In Wikipedia. Retrieved from http:/ / de.wikipedia.org/wiki/ Manager_\%28Wirtschaft $\% 29$

Organisation for Economic Co-operation and Development [OECD]. (2003). The PISA 2003 Assessment framework - mathematics, reading,science and problem solving knowledge and skills. Paris: OECD.

Skolverket. (2009). Upper secondary school, Syllabuses, Mathematics D. Retrieved 12 September 2009 from http: / / www.skolverket.se/sb/d/726/a/13845/func/ kursplan/id/3211/titleId / MA1204\%20-\%20Matematik\%20D

WebFinamce (2010). Manager. In Business dictionary. Retrieved from http: / / www.businessdictionary.com/definition/manager.html

\section{Authors}

Thomas Lingefjärd, University of Gothenburg, Box 300, SE 40530 Gothenburg, Sweden. Email: <Thomas.Lingefjard@gu.se>

Stefanie Meier, TU Dortmund (IEEM), Vogelpothsweg 87, 44221 Dortmund, Germany. E-Mail: <stefanie.meier@math.tu-dortmund.de> 